\title{
The Impact of Perfectionism on Mental, Social, and Physical Health of Graduate Students in the Health Sciences
}

Kelly B. Filipkowski

Misericordia University, kfilipkowski@misericordia.edu

Alicia H. Nordstrom

Misericordia University, anordstrom@misericordia.edu

Triet Pham

Rutgers University, tmp140@math.rutgers.edu

Michael Floren

University of North Alabama, mafloren@una.edu

Scott L. Massey

University of Pittsburgh, scottmasseyphd@outlook.com

Follow this and additional works at: https://nsuworks.nova.edu/ijahsp

Part of the Clinical Psychology Commons, Interprofessional Education Commons, Other Medicine and Health Sciences Commons, and the Social Psychology Commons

This Manuscript has supplementary content. View the full record on NSUWorks here: https://nsuworks.nova.edu/ijahsp/vol19/iss3/19

\section{Recommended Citation}

Filipkowski KB, Nordstrom AH, Pham T, Floren M, Massey SL. The Impact of Perfectionism on Mental, Social, and Physical Health of Graduate Students in the Health Sciences. The Internet Journal of Allied Health Sciences and Practice. 2021 Jan 01;19(3), Article 19.

This Manuscript is brought to you for free and open access by the College of Health Care Sciences at NSUWorks. It has been accepted for inclusion in Internet Journal of Allied Health Sciences and Practice by an authorized editor of NSUWorks. For more information, please contact nsuworks@nova.edu. 


\title{
The Impact of Perfectionism on Mental, Social, and Physical Health of Graduate Students in the Health Sciences
}

\begin{abstract}
Purpose: Perfectionism is considered a multidimensional construct with adaptive and maladaptive features. It was hypothesized that the diverse perfectionism components would predict well-being outcomes of similar valence. Method: The current study investigated perfectionism and mental, social, and physical health outcomes of graduate students in health science disciplines, across two semesters. We utilized two approaches in our empirical analysis. We first examined the continuous relationships between perfectionistic strivings, perfectionistic concerns, and health-related outcomes of graduate students. Additionally, we assessed differences between three perfectionism groups (i.e., adaptive, maladaptive, or non-perfectionist) on these well-being outcomes. Results: Results indicated that generally, adaptive perfectionism was related to better mental health, quality of life, and social functioning; maladaptive perfectionism was related to worse outcomes. The groups, however, did not statistically differ in general physical health. Conclusions: Overall, our results support a conceptualization of perfectionism that is differentially related to graduate student well-being. Thus, supportive networks may be fostered by differentiating between adaptive and maladaptive features of perfectionism. Moreover, we highlight the need for further discussion relative to determining perfectionism in high-achieving populations, in particular, graduate students in the health sciences.
\end{abstract}

\section{Author Bio(s)}

Kelly Filipkowski, PhD, is an Associate Professor of Psychology at Misericordia University.

Alicia Nordstrom, PhD, is a Professor of Psychology at Misericordia University.

Triet Pham, PhD, is an Assistant Teaching Professor of Mathematics and the Acting Director of the Master in Math Finance program at Rutgers University.

Michael Floren, PhD, is an Assistant Professor of Quantitative Methods for the Department of Finance, Economics, and Data Analytics at the University of North Alabama.

Scott Massey, PhD, PA-C, is an Associate Professor in the Department of Physician Assistant Studies at the University of Pittsburgh. 


\title{
TIJAHSP \\ The Internet Journal of Allied Health Sciences and Practice \\ Vol. 19 No. 3 ISSN 1540-580X
}

\section{The Impact of Perfectionism on Mental, Social, and Physical Health of Graduate Students in the Health Sciences}

\author{
Kelly B. Filipkowski ${ }^{1}$ \\ Alicia H. Nordstrom ${ }^{1}$ \\ Triet Pham ${ }^{2}$ \\ Michael Floren ${ }^{3}$ \\ Scott L. Massey 4 \\ 1. Misericordia University \\ 2. Rutgers University \\ 3. University of North Alabama \\ 4. University of Pittsburgh \\ United States
}

\begin{abstract}
Purpose: Perfectionism is considered a multidimensional construct with adaptive and maladaptive features. It was hypothesized that the diverse perfectionism components would predict well-being outcomes of similar valence. Method: The current study investigated perfectionism and mental, social, and physical health outcomes of graduate students in health science disciplines, across two semesters. We utilized two approaches in our empirical analysis. We first examined the continuous relationships between perfectionistic strivings, perfectionistic concerns, and health-related outcomes of graduate students. Additionally, we assessed differences between three perfectionism groups (i.e., adaptive, maladaptive, or non-perfectionist) on these well-being outcomes. Results: Results indicated that generally, adaptive perfectionism was related to better mental health, quality of life, and social functioning; maladaptive perfectionism was related to worse outcomes. The groups, however, did not statistically differ in general physical health. Conclusions: Overall, our results support a conceptualization of perfectionism that is differentially related to graduate student well-being. Thus, supportive networks may be fostered by differentiating between adaptive and maladaptive features of perfectionism. Moreover, we highlight the need for further discussion relative to determining perfectionism in highachieving populations, in particular, graduate students in the health sciences.
\end{abstract}

Keywords: perfectionism, health and well-being, graduate students, health sciences 


\section{INTRODUCTION}

The student experience of graduate education is rife with academic, social, emotional, and financial challenges. According to university reports of graduate student wellness, rates of depression and anxiety range from $41-46 \%$ which are roughly six times higher than the general population. ${ }^{1}$ One study compared rates of depression, anxiety, non-suicidal self-injury and suicidal ideation in approximately 10,000 masters' and 6,000 doctoral students. Data on nursing and medical graduate programs showed that 18$29 \%$ of masters' students and $13-20 \%$ of doctoral students reported one or more of these mental health symptoms. ${ }^{2}$ These data underscore "evidence for a growing mental health crisis in graduate education."1

According to the United States Department of State, the American education system of higher education, also known as postsecondary education, is "largely independent from federal government regulation and is highly decentralized." 3 Undergraduate education is typically bestowed after four years with a bachelor's degree. Masters degrees are 1-3 years following the bachelors' degree and doctoral degrees are typically 5-7 years after the bachelor's degree. ${ }^{4}$ Postsecondary universities and colleges may be "for profit" or "nonprofit" and may be public or private. Students in the United States have agency to pursue careers based on passion and interest but are required to meet admissions and entrance criteria that may include standardized testing, grade criteria from secondary schools, and other aspects (e.g., leadership, service).

Research on academic achievement has zeroed in on conscientiousness as the greatest predictor of academic success and grade point average. 5,6 However, stress and mental health challenges of graduate and medical students are often a consequence of high academic and performance demands related to their professional aspirations. ${ }^{7,8}$ One significant correlate to negative mental health outcomes in students is perfectionism, which has been linked to the pressures of academic achievement and concerns about failure. ${ }^{9}$

\section{Perfectionism Overview}

The term "perfectionism" generally elicits a negative connotation, one that is associated with many adverse outcomes.10 Researchers, however, have long considered it a multidimensional construct with potentially positive, even adaptive components, as well as negative, maladaptive components. Hamachek first made the distinction between normal perfectionists - those who appreciate and have confidence in their abilities and welcome challenges - and neurotic perfectionists as those who fear failure and are never satisfied with their achievements. ${ }^{11}$ Some widely-utilized scales in assessing perfectionism have focused on this multidimensional approach, such as Hewitt and Flett's Multidimensional Perfectionism Scale (MPS-HF), Frost and colleagues' Multidimensional Perfectionism Scale (MPS-F), and Slaney and colleagues' Almost Perfect Scale-Revised (APS-R). ${ }^{12-14}$

Although each of these measures of perfectionism differ in the specific items they use to determine perfectionism, they all illustrate the importance of parsing out those characteristics that are associated with high personal standards (e.g., adaptive perfectionism) from the negative thought patterns when those standards are not achieved (e.g., maladaptive perfectionism). That is, each measure is based on the premise that there are some perfectionistic characteristics, such as having ambitious goals, high standards of performance, and working at one's full potential, that are beneficial to individuals. In addition, there are different characteristics, such as extreme concerns about not meeting one's standards, and the negative beliefs that may result, that are potentially harmful to individuals. Specifically, researchers assert that it is only the maladaptive domain that is related to negative outcomes. ${ }^{15}$

\section{Perfectionism, Mental Health, and Quality of Life}

Perfectionism and many of its multifaceted components have been associated with various psychopathological outcomes. ${ }^{16}$ More specifically, maladaptive perfectionism has been associated with indices of poor adjustment and general psychopathology in college students, anxiety sensitivity, lower self-esteem and higher self-criticism, depression, and reduced life satisfaction., 12,17-24 Additionally, maladaptive perfectionism has been related to hopelessness and suicidal ideation, as well as future likelihood of suicide. 8,25 To the contrary, adaptive perfectionism may relate to positive outcomes, such as being a buffer against burnout and a positive predictor of components of life satisfaction. ${ }^{20,26,27-30}$ Thus, aspects of perfectionism may differentially relate to mental health and perceptions of life satisfaction.

\section{Perfectionism and Social Functioning}

Components of perfectionism have been suggested as leading to diverse social outcomes as well. Adaptive perfectionism has been associated with having a higher number of and more enjoyable social relationships, as well as higher emotional sensitivity and social expressiveness. ${ }^{22,31}$ Maladaptive perfectionism, however, has been associated with fewer leisure activities and social relationships, as well as a higher frequency of negative social interaction, and lower perceived social support, irrespective of the actual support received. 19,22,32 Maladaptive perfectionism has also been related to higher levels of loneliness, shyness, fear of negative evaluation, lower emotional-expressiveness, higher emotional control, greater social sensitivity, as well as perfectionistic self-promotion and avoidance of displaying imperfection, validation seeking and rejection sensitivity, and lack of disclosure. ${ }^{31,33-35}$ 
This is of particular importance given the association of disclosure with positive mental and physical health outcomes and lack of disclosure with deleterious ones. ${ }^{36}$ Thus, for college students high in maladaptive perfectionism, the desire to maintain a perfect impression and unwillingness to disclose a less than perfect self may result not only in unsatisfying social interactions, but physical health consequences as well.

\section{Perfectionism and Physical Health}

Whereas the literature is replete regarding the connection between perfectionism and mental health, less is known about the relationship between perfectionism and physical health. Despite this, a similar pattern emerges such that maladaptive perfectionism has been shown to be associated with higher self-reported physical symptoms and somatic complaints in college and community samples. ${ }^{12,37-43}$ Maladaptive perfectionism has also been associated with specific conditions, such as chronic fatigue syndrome, mental and physical fatigue, as well as pain interference. ${ }^{44-46}$ Evidence, however, is mixed regarding the relationship between adaptive perfectionism and physical health; some have found it related to worse health, and others demonstrated its relation to better health.42,43,47Although a connection between perfectionism and physical health has been established among college students, we propose continued research in order to examine the complex nature of this relationship.

\section{The Current Study}

Previous research has demonstrated two distinct (albeit, overlapping) dimensions of perfectionism, namely adaptive and maladaptive perfectionism, that are differentially related to well-being. ${ }^{15}$ We suggest that these aspects of perfectionism will differentially predict social, mental, and physical health outcomes. Thus, the goal of this study was to examine the relationship between subscales of Frost and colleagues' Multidimensional Perfectionism Scale (MPS-F) and mental health, quality of life, social functioning, and physical health of college students. ${ }^{13}$ Whereas the majority of studies investigating perfectionism have involved undergraduate students, our study examined perfectionism in health sciences graduate students, a relatively higher-achieving population. Although some studies have examined perfectionism in graduate students, they have been primarily focused on academically-related outcomes. ${ }^{48-52}$ To extend and broaden this literature, we conducted a prospective assessment of the relationship between perfectionism and mental, social, and physical health across two semesters of graduate school in health sciences disciplines.

Perfectionism research has been categorized into two conceptualizations: 1) dimensional conceptions, which take into account maladaptive and adaptive subscales and their relation to various outcomes, and 2) group-based conceptions, which compare adaptive, maladaptive, and non-perfectionists. ${ }^{15}$ The present study utilized both approaches in our empirical analysis of positive and negative features of perfectionism and the effects on graduate students' mental, social, and physical health. Specific to the MPS-F, Frost and colleagues demonstrated that the various subscales of the MPS-F could be divided into two primary factors, one related to positive strivings and one related to perfectionistic concerns (see Stoeber and Otto review for a more in-depth discussion). ${ }^{15,53}$ Therefore, we first examined the elements that comprise the perfectionistic concerns and positive strivings conceptualizations of the MPS-F (see measures for specific subscale information). ${ }^{53}$ Specifically, we predicted that positive strivings would be associated with better self-reported mental and physical health, as well as higher quality of life and social functioning. Contrary to this, perfectionistic concerns were expected to be related to worse self-reported mental and physical health, quality of life, and social functioning. In order to assess differences among perfectionism types, we categorized the participants into one of three groups: adaptive, maladaptive, or non-perfectionist. We expected adaptive perfectionists to fare best on our mental, social, and physical health dependent measures.

\section{METHODS \\ Participants}

A total of 92 health sciences graduate students from a small northeastern university, in the United States, participated in the current study. Participants ranged in age from $20-41$ years $(M=22.11, S D=3.11) ; 91 \%$ were Caucasian, and $82 \%$ were female.

\section{Procedure}

The data used for the current study was part of a larger, two-year longitudinal study of mental and physical health in four graduate health sciences programs (Physical Therapy, Occupational Therapy, Speech-Language Pathology, and Physician Assistant). Ethical approval to conduct the study was provided by the University's Institutional Review Board (Approval \#25-13-T3). Students who opted to participate, first signed informed consent forms, which provided them with an overview of the study protocol, and their rights as participants, including the voluntary nature of their participation, and the ability to withdraw from the study at any time, without penalty. Students provided baseline data during the first week of their graduate program and then again at midterms during each of the four semesters of their program (with one week to complete them). Students received a $\$ 10$ Amazon.com gift certificate as compensation at each time point. The measures used in the current study were collected at midterms of the participants' first and second semesters of graduate school. 


\section{Measures \\ Perfectionism}

The 35-item MPS-F is a widely used measure that assesses six dimensions of perfectionism: concern over mistakes, personal standards, parental expectations, parental criticism, doubts about actions, and organization. ${ }^{13}$ Responses vary on a Likert scale from 1 (strongly disagree) to 5 (strongly agree) with higher scores indicating higher perfectionism. Cronbach's alphas for data from the current study demonstrated almost identical levels $(.78<a<.93)$ as other studies. ${ }^{13}$ Based on recommendations of Stoeber and Otto's review suggesting the removal of parental expectations, parental criticism, and organization subscales, the subscales were re-coded into perfectionistic strivings, which consists of the personal standards subscale (e.g., I have extremely high goals), and perfectionistic concerns, a summative composite of the concerns over mistakes (e.g., I should be upset if I make a mistake) and doubts about actions subscales (e.g., I usually have doubts about the simple everyday things I do). ${ }^{15}$

\section{Mental Health, Social Functioning, and Physical Health}

The RAND 36-item Health Survey Version 1.0 assesses eight health-related domains (physical functioning, bodily pain, role limitations due to physical health, role limitations related to personal or emotional problems, mental health, social functioning, energy/fatigue, and general health). ${ }^{54}$ Three scales from the RAND Health Survey were utilized in the current study: a five-item scale of mental health, a two-item scale of social functioning, and a five-item scale measuring general physical health. The items are identical to the Medical Outcomes Study Short Form-36, a widely-used measure with strong evidence of reliability and validity. 55,56 Scale scores are created within the RAND norm-based computer program, range from 0 to 100 , and represent the percentage of total possible score achieved. Scores within the same scales are then averaged, with higher scores indicating more favorable health in that domain.

\section{Quality of Life (QOL)}

The Quality of Life Inventory measures satisfaction in 16 areas: health, self-esteem, goals-and-values, money, work, play, learning, creativity, helping, love, friends, children, relatives, home, neighborhood, and community. ${ }^{57,58}$ For each domain, participants indicated its importance to their happiness on a scale ranging from 0 (not important) to 2 (extremely important), as well as their satisfaction with that dimension, ranging from -3 (very dissatisfied) to 3 (very satisfied). Overall raw scores were automatically converted into T-scores using the computer-scored version of the QOL; higher scores indicate higher overall QOL. The QOL Inventory has demonstrated good reliability $(\alpha=.77)$ and validity. 57,58

\section{RESULTS \\ Analytic Strategy}

In order to explore the continuous relationships between our independent and dependent measures, we calculated correlations between perfectionistic strivings and our social, physical, and mental health outcomes at both Time 1 (the mid-point of the first semester) and Time 2 (the mid-point of the second semester). We also calculated the correlations between perfectionistic concerns and each of the dependent variables at both time points. Moreover, as there was a moderate, positive correlation between perfectionistic strivings and perfectionistic concerns $(r=0.43)$, we conducted partial correlations in order to rule out potential suppression effects of perfectionistic concerns. ${ }^{15}$

In order to compare across perfectionism types, we categorized participants into one of three perfectionism groups (i.e., maladaptive, adaptive, and non-perfectionists) based on median splits of our perfectionistic strivings (Median = 26) and perfectionistic concerns (Median $=34$ ) variables. Specially, those considered adaptive perfectionists $(N=16)$ had high strivings and low concerns scores; those considered maladaptive perfectionists $(N=28)$ had high strivings and high concerns scores; and nonperfectionists $(N=48)$ were those who had low strivings scores, irrespective of their concerns score. ${ }^{15}$ We utilized a general linear mixed model (GLMM) via R statistical software to assess differences in perfectionism groups while accounting for time across the two semesters. ${ }^{59}$ The exception is QOL, which was only measured during the first semester.

\section{Correlations and Partial Correlations}

Contrary to our hypotheses, all correlations indicated non-significant negative associations between perfectionistic strivings and our dependent measures. After perfectionistic concerns were removed from the data, all correlations moved in the expected direction (towards a positive association between strivings and most outcome measures), similar to prior research..$^{15}$ See Table 1. We conducted the same procedures for perfectionistic concerns, as well. As expected, correlations between perfectionistic concerns and the dependent measures were negatively related to all outcomes at both time points, both before and after controlling for perfectionistic strivings. 
Table 1. Pearson's and partial correlations for perfectionistic strivings, perfectionist concerns, and wellbeing outcomes during the first two semesters of graduate school.

\begin{tabular}{|c|c|c|c|c|c|c|c|c|}
\hline \multirow{3}{*}{ Outcome measures } & \multicolumn{4}{|c|}{ Perfectionistic Strivings } & \multicolumn{4}{|c|}{ Perfectionistic Concerns } \\
\hline & \multicolumn{2}{|c|}{ First semester } & \multicolumn{2}{|c|}{ Second semester } & \multicolumn{2}{|c|}{ First semester } & \multicolumn{2}{|c|}{ Second semester } \\
\hline & $r$ & Partial & $r$ & Partial & $r$ & Partial & $r$ & Partial \\
\hline Mental health & -0.084 & 0.159 & -0.174 & 0.014 & $-0.487^{* * t}$ & $-0.501^{* * *}$ & $-0.376^{* *}$ & $-0.338^{* *}$ \\
\hline QOL & -0.118 & 0.142 & $\mathrm{~N} / \mathrm{A}$ & $N / A$ & $-0.539^{* * *}$ & $-0.544^{*+* x}$ & $N / A$ & $\mathrm{~N} / \mathrm{A}$ \\
\hline Social functioning & -0.106 & 0.094 & $-0.235^{*}$ & -0.066 & $-0.426^{* * *}$ & $-0.423^{*+* x}$ & $-0.370^{* *}$ & $-0.300^{* *}$ \\
\hline Physical health & -0.118 & 0.021 & -0.127 & -0.056 & $-0.318^{* *}$ & $-0.297^{* *}$ & -0.161 & -0.114 \\
\hline $\begin{array}{l}\text { lote: } \mathrm{QOL} \text { was only } \mathrm{n} \\
p<0.05 \\
p<0.01 \\
{ }^{*} p<0.001\end{array}$ & & & & & & & & \\
\hline
\end{tabular}

\section{Perfectionism Types}

The mental health of the three perfectionism groups (adaptive perfectionists, maladaptive perfectionists, and non-perfectionists) was significantly different across time, $F(2,87.95)=3.68, p=.029, \omega^{2}=.056$. GLMM coefficients indicated that adaptive perfectionists were statistically significantly higher in mental health scores than maladaptive perfectionists $(p=.003)$. Non-perfectionists were marginally lower than adaptive perfectionists $(p=.067)$, and marginally higher than maladaptive perfectionists $(p=.078)$. See Table 2 for means and standard deviations of all three groups during each semester.

An ANOVA revealed a significant difference between the three groups in regards to $Q O L$ during the first semester, $F(2,86)=5.64$, $p=.005, \omega^{2}=.095$. Tukey's pairwise tests indicated that adaptive perfectionists were significantly higher in QOL than maladaptive perfectionists $(p=.003)$, and marginally higher than non-perfectionists $(p=.069)$. There was no evidence of a significant difference between maladaptive perfectionists and non-perfectionists ( $p=.211$; see Table 2$)$.

GLMM indicated a marginal difference between the three groups in regards to social functioning across the two semesters, $F(2,88.41)=2.84, p=.064, \omega^{2}=.039$, such that maladaptive perfectionists were statistically significantly lower than average ( $\left.p=.026\right)$. There were no significant differences in general physical health between adaptive perfectionists, maladaptive perfectionists, and non-perfectionists across semesters, $F(2,85.52)=0.466, p=.629, \omega^{2}=-.012$ (see Table 2). 
Table 2. Means and standard deviations of mental health, quality of life (QOL), social functioning, and general physical health outcomes for adaptive perfectionists, maladaptive perfectionists, and non-perfectionists.

\begin{tabular}{|c|c|c|c|c|c|c|}
\hline \multirow[b]{3}{*}{ Outcome variable } & \multicolumn{6}{|c|}{ Time 1 - First semester of graduate school } \\
\hline & \multicolumn{2}{|c|}{$\begin{array}{l}\text { Adaptive perfectionists } \\
\qquad N=16\end{array}$} & \multicolumn{2}{|c|}{$\begin{array}{l}\text { Maladaptive perfectionists } \\
\qquad N=28\end{array}$} & \multicolumn{2}{|c|}{$\begin{array}{c}\text { Non-perfectionists } \\
N=48\end{array}$} \\
\hline & $\mathrm{M}$ & SD & $\mathrm{M}$ & SD & $\mathrm{M}$ & SD \\
\hline Mental health & 73.05 & 10.81 & 57.32 & 20.16 & 64.27 & 16.18 \\
\hline QOL & 55.00 & 6.74 & 44.23 & 11.76 & 48.43 & 10.03 \\
\hline Social functioning & 88.28 & 15.46 & 77.68 & 29.92 & 85.42 & 18.83 \\
\hline \multirow[t]{3}{*}{ Physical health } & 73.50 & 19.05 & 69.50 & 20.39 & 74.38 & 18.11 \\
\hline & \multicolumn{6}{|c|}{ Time 2 - Second semester of graduate school } \\
\hline & \multicolumn{2}{|c|}{$\begin{array}{c}\text { Adaptive perfectionists } \\
\qquad N=13\end{array}$} & \multicolumn{2}{|c|}{$\begin{array}{l}\text { Maladaptive perfectionists } \\
\qquad N=25\end{array}$} & \multicolumn{2}{|c|}{$\begin{array}{l}\text { Non-perfectionists } \\
\qquad N=39\end{array}$} \\
\hline Outcome variable & $\mathrm{M}$ & SD & $\mathrm{M}$ & SD & $\mathrm{M}$ & SD \\
\hline Mental health & 71.54 & 16.51 & 63.00 & 18.20 & 70.38 & 14.39 \\
\hline QOL & \multicolumn{2}{|c|}{$\mathrm{N} / \mathrm{A}$} & \multicolumn{2}{|c|}{$\mathrm{N} / \mathrm{A}$} & \multicolumn{2}{|c|}{$\mathrm{N} / \mathrm{A}$} \\
\hline Social functioning & 82.69 & 23.13 & 74.50 & 23.24 & 86.54 & 15.81 \\
\hline Physical health & 75.54 & 16.47 & 74.28 & 12.30 & 77.62 & 12.74 \\
\hline
\end{tabular}

Note: QOL was only measured during the first semester.

\section{Post-hoc Exploratory Analyses}

The perfectionistic strivings scale ranges between 7 and 35; however, in our sample, the mean (26.35) and median (26.00) values were quite high, similar to studies with medical students. ${ }^{8}$ Even the minimum score (18) was still more than $50 \%$ of the scale's highest possible score. We considered that maybe all graduate students in health sciences, given their high aspirational goals, could be considered perfectionists - at least if we are using high strivings scores as the defining criteria. We conducted a sensitivity analysis to examine this hypothesis treating all participants as perfectionists with high perfectionistic strivings scores; the distinction between high and low concerns remained the same as in our original analyses. In this exploratory strategy, $N=47$ were classified as adaptive and $N=46$ were considered maladaptive perfectionists.

The mental health of adaptive and maladaptive perfectionists was statistically significantly different across time, $F(1,91.52)=17.26$, $p<.001, \omega^{2}=.149$. Moreover, there was a significant difference between adaptive and maladaptive perfectionists in their QOL during the first semester, $F(1,88)=15.13, p<.001, \omega^{2}=.137$. Interestingly, adaptive perfectionists and maladaptive perfectionists also demonstrated statistically significant differences in physical health, $F(1,87.61)=4.67, p=.033, \omega^{2}=.040$, and social functioning $F(1,92.29)=8.86, p=.003, \omega^{2}=.078$, across the two semesters. In sum, exploratory analyses demonstrated that adaptive perfectionists were statistically significantly better on mental, social, and physical health outcomes.

\section{DISCUSSION}

We predicted that perfectionistic strivings (i.e., adaptive perfectionism) would be related to better mental health, physical health, quality of life (QOL), and social functioning, and perfectionistic concerns (i.e., maladaptive perfectionism) would be associated with worse outcomes. Moreover, we expected that adaptive perfectionists would report better social, mental, and physical health, as well as QOL, when compared to non-perfectionists and maladaptive perfectionists. Overall, our results support this assertion that perfectionism is a multi-dimensional construct that differentially predicts functioning. Although examining the dimensions as separate entities allows researchers to parse out those features of perfectionism that differentially predict mental and physical health outcomes, in reality these dimensions operate together simultaneously. Examining the groups (i.e., types of perfectionism), thus, accounts for differing combinations of perfectionistic strivings and concerns that co-occur within the individual. 


\section{Perfectionism, Mental Health and Quality of Life}

Our measure of mental health inquired about feelings along two continuums concerning sadness/happiness as well as nervousness/calmness. As expected, adaptive perfectionists reported the highest levels of mental health and maladaptive perfectionists reported the lowest levels. This is consistent with other research that has demonstrated an association between maladaptive perfectionism and depression, as well as anxiety. $.16,17,19,32,60$ This difference in mental health functioning may be of particular importance for health science students, and in particular those with maladaptive perfectionism, given the high expectations and rigorous environments of graduate programs. This is purely speculative, as stress was not directly tested in the current study, however, its contextual contribution to health science students' psychological functioning has been welldocumented in previous studies. ${ }^{61,62}$ Moreover, as stress has been shown to (at least partially) mediate the relationship between maladaptive perfectionism and poorer psychological functioning, this would warrant further research into the mechanisms related to the differences in mental health among adaptive and maladaptive perfectionists. ${ }^{63-67}$

In our study, adaptive perfectionists also reported the highest levels of QOL, consistent with prior studies demonstrating that adaptive perfectionists exhibited higher life satisfaction (or various domains of life satisfaction) than maladaptive perfectionists. ${ }^{20,27-30}$ Maladaptive perfectionists fared worst in regards to QOL, similar to previous research. ${ }^{23,24}$ There were no significant differences between maladaptive and non-perfectionists, which directly parallels research conducted by Öngen, yet contradicts research that has demonstrated both types of perfectionists to fare better than non-perfectionists. ${ }^{28-30}$

\section{Perfectionism and Social Functioning}

Our findings that maladaptive perfectionists reported the lowest levels of social functioning was expected, as several studies have suggested that adaptive perfectionism is related to social connection, and maladaptive perfectionism is related to social disconnection. ${ }^{32,68,69}$ Although studies have demonstrated that both adaptive and maladaptive perfectionists tend to be better at perspective taking and less disruptive than non-perfectionists, current findings may be a reflection of our social functioning measure. 70,71 The RAND assesses how often the participants' physical or emotional well-being prevents them from engaging in social activities - as opposed to assessing levels of social competence. Therefore, the lowered social functioning of maladaptive perfectionists in our sample may be due to self-imposed factors such as social withdrawal, perhaps stemming from a fear of negative evaluation. . $^{11,34}$

\section{Perfectionism and General Physical Health}

Unlike previous research that has found a relationship between maladaptive perfectionism and physical symptoms, we found no statistically significant differences in general physical health among the different types of perfectionists. ${ }^{37,40,42}$ It is possible that perfectionism is less associated with general health perceptions than we had anticipated. The health survey we used measured self-perceptions of general health, as opposed to a more specific symptom checklist. Of the studies investigating the relationship between maladaptive perfectionism and physical health, several have demonstrated that the relationship is due, specifically, to the tension/fatigue and pain interference subscales of the symptom checklists. $42,44,46$ Therefore, perfectionism may impact physical symptoms, and in particular those related to chronic fatigue and pain, more than general health perceptions.

Another plausible explanation may reside in our conceptualization of perfectionism in the original analyses. That is, our exploratory analyses (i.e., categorizing the entire sample as perfectionist, due to relatively high personal standards in all participants) revealed that adaptive perfectionists reported significantly less problems with physical health compared to maladaptive perfectionists. Stress has been shown to impact the relationship between maladaptive perfectionism and physical symptoms, however, only for those at high levels of stress. ${ }^{72}$ Thus, the relationship for poorer outcomes for maladaptive perfectionists appear particularly potent when individuals are experiencing high levels of stress. Given that we did not directly assess stress, and our results are exploratory in nature, this is purely speculative and worthy of deeper study.

\section{Fostering Supportive Learning Environments for Perfectionists in the Health Sciences}

Perfectionism, including maladaptive perfectionism, is on the rise. ${ }^{73}$ Therefore, it is imperative to provide supportive environments for graduate students - a group that is often underserved. The collective results, however, imply that perfectionism is multidimensional in nature and that not all perfectionism is necessarily damaging. Indeed, Gnilka and colleagues have suggested that counselors aid students in developing positive coping strategies by acknowledging the adaptive components of perfectionism and reducing and/or modifying only those harmful maladaptive components. ${ }^{20}$ Interventions such as Cognitive Behavioral Therapy (CBT) have been shown to reduce maladaptive perfectionism. ${ }^{74}$ Moreover, mindfulness interventions have evidenced reductions in rumination and biological markers of stress, as well as elevated self-compassion among graduate students in speech-language pathology. ${ }^{75}$ 
A randomized controlled trial of a six-week Acceptance and Commitment Therapy (ACT) intervention (compared to a study tips control) improved test performance and psychological flexibility of graduate students in a behavior analysis program. ${ }^{7}$ The level of stress remained the same for both conditions despite these differences which points to the nature and components of the ACT intervention as beneficial influences on academic and emotional health. ACT focuses on increasing valued-based actions, awareness of emotions, emotional distance from thoughts, and acceptance (as opposed to avoidance) of all emotions, including negative and difficult ones. ${ }^{76}$

The ACT concept of psychological flexibility may be one antidote to maladaptive perfectionism and can be promoted by surrounding influencers of student behavior such as instructors, support staff, coaches, and parents. ${ }^{76} \mathrm{It}$ is common for health educators to remind students of the "make it or break it" mantra that will dictate the trajectory of their future career. These threatening messages are likely to facilitate maladaptive perfectionism by minimizing students' internal motivation for mastery learning and maximizing students' motivation for external benchmarks such as grades. Having educators shift their messaging to promote psychological flexibility will enable students to internalize a healthy mindset towards stress (e.g., accepting stress as a part of the graduate school experience but without threat or judgment) and focus on value-driven actions instead of fear-based actions. For example, Palilunas and colleagues found that students who completed the ACT intervention reported higher levels of self-identified importance of education compared to the control group. ${ }^{7}$ Educators can positively motivate students and de-emphasize maladaptive perfectionism by keeping students grounded in how their graduate program is contributing to their future success, praising effort as opposed to academic outcomes, and reminding students about their passion and reasons for pursuing their career. Moreover, these types of interventions may be of particular benefit during the first semester of graduate school, as anxiety of health science students has been shown to increase during their first semester. ${ }^{77}$

\section{Limitations}

Although our research provides further evidence regarding the distinction between adaptive and maladaptive perfectionism and the diverse outcomes associated with each, we encountered some psychometric and methodological limitations. Our measures were based on self-reports and perceptions of mental, social, and physical health; thus, more objective assessments, particularly regarding physical health, would be beneficial. Given that our data collection occurred at a rural, small liberal-arts university, we were limited to a homogenous demographic sample and a small number of health-focused graduate programs. Therefore, our results may not generalize to larger, more diverse populations and types of graduate programs. We did, however, have several results that are similar to those of larger institutions, indicating that our samples may be more similar than different.

In regards to measurement, our measure of perfectionism was assessed concurrently with our other dependent measures during the first semester, limiting our ability to generalize and infer causality. We attempted to strengthen this by including a more prospective assessment and analyzing our relationships across the two semesters, however a longer longitudinal timeframe would provide a more holistic view of the students' long-term success.

\section{Recommendations for Future Research}

The limitations of our study delineate parameters for future research that will refine our understanding of the ways in which aspects of perfectionism affect the mental and physical health of graduate students in the health sciences. For example, additional research is needed to clarify the differential social outcomes of perfectionism and the mechanism underlying maladaptive perfectionists' social impairments. Future research should also parse out the relationship between perfectionism and general physical health perceptions, as well as specific symptomology. Moreover, many studies have demonstrated an indirect relationship between perfectionism and health via important mediators such as health behaviors, self-concealment, self-efficacy, affect, as well as social support and stress..$^{24,38-41,47}$ Thus, future research should continue exploring a more indirect route to understanding links between perfectionism and physical health. Lastly, we suggest that it is necessary to determine the most appropriate method by which to distinguish perfectionist from non-perfectionist, particularly in samples that consist primarily of individuals with high personal standards (e.g., graduate students in health sciences disciplines). For instance, researchers have suggested the need to reevaluate the use of the personal standards scales and adopt more advanced statistical modeling in differentiating perfectionists from non-perfectionists. ${ }^{78}$

\section{CONCLUSION}

The objective of our study was to examine the role of maladaptive and adaptive perfectionism on the mental, social, and physical health of graduate students in the health sciences. We utilized two approaches in examining these relationships, one focused on dimensions of perfectionism (i.e., perfectionistic strivings and concerns), and the other a combination of these two dimensions into groups, as reflected in different types of perfectionism (i.e., maladaptive, adaptive, and non-perfectionists). In our study, the perfectionistic strivings dimension was generally not related to our dependent outcomes. Higher concerns, however, was associated with worse mental health, social functioning, QOL, and general physical health. Adaptive perfectionists were most likely 
to report better mental health, QOL, and social functioning; there were no differences in physical health among the perfectionism groups. Results of the present study reinforce the multidimensional conceptualization of perfectionism, even among graduate students, who generally have high personal standards and are engaged in a highly stressful context. We encourage further exploration of the underlying mechanisms of perfectionism dimensions and how they may predict the social, emotional, physical functioning, and life satisfaction of graduate students in the health sciences.

\section{REFERENCES}

1. Evans TM, Bira L, Gastelum JB, Weiss LT, Vanderford NL. Evidence for a mental health crisis in graduate education. Nat Biotechnol. 2018;36(3):282-284. [PMID 29509732]

2. Lipson SK, Zhou S, Wagner B, III, Beck K, Eisenberg D. Major differences: Variations in undergraduate and graduate student mental health and treatment utilization across academic disciplines. J College Stud Psychother. 2016;30(1):23-41.

3. Education USA. Understanding U.S. higher education. United States Department of State. Retrieved February 1, 2021 from https://educationusa.state.gov/foreign-institutions-and-governments/understanding-us-higher-education.

4. U.S. Department of Education, International Affairs Staff, Educational Publications Center. Education in the United States: A Brief Overview, Washington, D.C., 2005. Retrieved February 1, 2021 from https://www2.ed.gov/about/offices/list/ous/international/edus/index.html

5. McAbee ST, Oswald FL. The criterion-related validity of personality measures for predicting GPA: A meta-analytic validity competition. Psychol Assess. 2013;25(2):532-544. [PMID 23397931]

6. Rimfeld K, Kovas Y, Dale PS, Plomin R. True grit and genetics: Predicting academic achievement from personality. J Pers Soc Psychol. 2016;111(5):780-789. [PMID 26867111]

7. Paliliunas $D$, Belisle J, Dixon MR. A randomized control trial to evaluate the use of acceptance and commitment therapy (ACT) to increase academic performance and psychological flexibility in graduate students. Behav Anal Pract. 2018;11(3):241-253. [PMID 30363765]

8. Enns MW, Cox BJ, Sareen J, Freeman P. Adaptive and maladaptive perfectionism in medical students: A longitudinal investigation. Med Educ. 2001;35(11):1034-1042. [PMID 11703639]

9. Crosby JM, Armstrong AB, Nafziger MA, Twohig MP. Using acceptance and commitment therapy (ACT) to treat perfectionism in college students. In: Pistorello J, ed. Mindfulness and acceptance for counseling college students: Theory and practical applications for intervention, prevention and outreach. Oakland, CA: Context Press/New Harbinger Publications; 2013:139-158.

10. Pacht AR. Reflections on perfection. Am Psychol. 1984;39(4):386-390.

11. Hamachek DE. Psychodynamics of normal and neurotic perfectionism. Psychology: A Journal of Human Behavior. 1978;15(1):27-33.

12. Hewitt PL, Flett GL. Perfectionism in the self and social contexts: Conceptualization, assessment, and association with psychopathology. J Pers Soc Psychol. 1991;60(3):456-470. [PMID 2027080]

13. Frost RO, Marten P, Lahart C, Rosenblate R. The dimensions of perfectionism. Cognit Ther Res. 1990;14(5):449-468.

14. Slaney RB, Rice KG, Mobley M, Trippi J, Ashby JS. The Revised Almost Perfect Scale. Meas Eval Couns Dev. 2001;34(3):130-145.

15. Stoeber J, Otto K. Positive Conceptions of Perfectionism: Approaches, Evidence, Challenges. Pers Soc Psychol Rev. 2006;10(4):295-319. [PMID 17201590]

16. Shafran R, Mansell W. Perfectionism and psychopathology: A review of research and treatment. Clin Psychol Rev 2001;21(6):879-906. [PMID 11497211]

17. Flett GL, Greene A, Hewitt PL. Dimensions of Perfectionism and Anxiety Sensitivity. J Ration Emot Cogn Behav Ther. 2004;22(1):39-57.

18. Grzegorek JL, Slaney RB, Franze S, Rice KG. Self-Criticism, Dependency, Self-Esteem, and Grade Point Average Satisfaction Among Clusters of Perfectionists and Nonperfectionists. J Couns Psychol. 2004;51(2):192-200.

19. Flett GL, Hewitt PL, Garshowitz M, Martin TR. Personality, negative social interactions, and depressive symptoms. Can J Behav Sci 1997;29(1):28-37.

20. Gnilka PB, Ashby JS, Noble CM. Adaptive and maladaptive perfectionism as mediators of adult attachment styles and depression, hopelessness, and life satisfaction. J Couns Dev. 2013;91(1):78-86.

21. Wei M, Heppner PP, Russell DW, Young SK. Maladaptive perfectionism and ineffective coping as mediators between attachment and future depression: A prospective analysis. J Couns Psychol. 2006;53(1):67-79.

22. Wong DFK, Chan KS, Lau Y. The role of perfectionism and dysfunctional attitudes in depression and quality of life of a community sample of Chinese adults in Hong Kong. Int J Ment Health. 2010;39(4):40-48.

23. Stoeber J, Stoeber FS. Domains of perfectionism: Prevalence and relationships with perfectionism, gender, age, and satisfaction with life. Pers Individ Dif. 2009;46(4):530-535. 
24. Williams CJ, Cropley M. The relationship between perfectionism and engagement in preventive health behaviours: The mediating role of self-concealment. J Health Psychol. 2014;19(10):1211-1221. [PMID 23740260]

25. Roxborough HM, Hewitt PL, Kaldas J, et al. Perfectionistic self-presentation, socially prescribed perfectionism, and suicide in youth: A test of the Perfectionism Social Disconnection Model. Suicide Life Threat Behav. 2012;42(2):217-233. [PMID 22380005]

26. Hill AP, Curran T. Multidimensional perfectionism and burnout: A meta-analysis. Pers Soc Psychol Rev. 2016;20(3):269288. [PMID 26231736]

27. Çapan BE. Relationship among perfectionism, academic procrastination and life satisfaction of university students. Procedia Soc Behav Sci. 2010;5:1665-1671.

28. Gilman R, Ashby JS. A first study of perfectionism and multidimensional life satisfaction among adolescents. J Early Adolesc. 2003;23(2):218-235.

29. Gilman R, Ashby JS, Sverko D, Florell D, Varjas K. The relationship between perfectionism and multidimensional life satisfaction among Croatian and American youth. Pers Individ Dif. 2005;39(1):155-166.

30. Öngen DE. The relationship between perfectionism and multidimensional life satisfaction among high school adolescents in Turkey. J Multicult Couns Devel. 2009;37(1):52-64.

31. Flett GL, Hewitt PL, De Rosa T. Dimensions of perfectionism, psychosocial adjustment, and social skills. Pers Individ Dif. 1996;20(2):143-150.

32. Sherry SB, Law A, Hewitt PL, Flett GL, Besser A. Social support as a mediator of the relationship between perfectionism and depression: A preliminary test of the social disconnection model. Pers Individ Dif. 2008;45(5):339-344.

33. Flett GL, Besser A, Hewitt PL. Perfectionism and interpersonal orientations in depression: An analysis of validation seeking and rejection sensitivity in a community sample of young adults. Psychiatry: Interpersonal and Biological Processes. 2014;77(1):67-85. [PMID 24575914]

34. Hewitt PL, Flett GL, Sherry SB, Habke M, Parkin M, Lam RW, et al. The interpersonal expression of perfection: Perfectionistic self-presentation and psychological distress. J Pers Soc Psychol. 2003;84(6):1303-1325. [PMID 12793591]

35. Kawamura KY, Frost RO. Self-Concealment as a Mediator in the Relationship Between Perfectionism and Psychological Distress. Cognit Ther Res. 2004;28(2):183-191.

36. Pennebaker JW, Chung CK. Expressive writing: Connections to physical and mental health. In: Friedman HS, Friedman HS, eds. The Oxford handbook of health psychology. New York, NY, US: Oxford University Press; 2011:417-437.

37. Chang EC, Ivezaj V, Downey CA, Kashima Y, Morady AR. Complexities of measuring perfectionism: Three popular perfectionism measures and their relations with eating disturbances and health behaviors in a female college student sample. Eat Behav. 2008;9(1):102-110. [PMID 18167328]

38. Harrison F, Craddock AE. How attempts to meet others' unrealistic expectations affect health: Health-promoting behaviours as a mediator between perfectionism and physical health. Psychol Health Med. 2016;21(3):386-400. [PMID 26167729]

39. Martin TR, Flett GL, Hewitt PL, Krames L, Szanto G. Personality correlates of depression and health symptoms: A test of a self-regulation model. J Res Pers. 1996;30(2):264-277.

40. Molnar DS, Reker DL, Culp NA, Sadava SW, DeCourville NH. A mediated model of perfectionism, affect, and physical health. J Res Pers. 2006;40(5):482-500.

41. Molnar DS, Sadava SW, Flett GL, Colautti J. Perfectionism and health: A mediational analysis of the roles of stress, social support and health-related behaviours. Psychol Health. 2012;27(7):846-864. [PMID 22149004]

42. Saboonchi F, Lundh L-G. Perfectionism, anger, somatic health, and positive affect. Pers Individ Dif. 2003;35(7):1585-1599.

43. Sirois FM, Molnar DS. Perfectionistic strivings and concerns are differentially associated with self-rated health beyond negative affect. J Res Pers. 2017;70:73-83.

44. White $C$, Schweitzer R. The role of personality in the development and perpetuation of chronic fatigue syndrome. $J$ Psychosom Res. 2000;48(6):515-524. [PMID 11033370]

45. Dittner AJ, Rimes K, Thorpe S. Negative perfectionism increases the risk of fatigue following a period of stress. Psychol Health. 2011;26(3):253-268. [PMID 20204976]

46. Hadjistavropoulos H, Dash H, Hadjistavropoulos T, Sullivan T-L. Recurrent pain among university students: Contributions of self-efficacy and perfectionism to the pain experience. Pers Individ Dif. 2007;42(6):1081-1091.

47. Flett GL, Panico T, Hewitt PL. Perfectionism, type A behavior, and self-efficacy in depression and health symptoms among adolescents. Current Psychology: A Journal for Diverse Perspectives on Diverse Psychological Issues. 2011;30(2):105-116.

48. Comerchero V, Fortugno D. Adaptive perfectionism, maladaptive perfectionism and statistics anxiety in graduate psychology students. Psychology Learning \& Teaching. 2013;12(1):4-11.

49. Cowie ME, Nealis LJ, Sherry SB, Hewitt PL, Flett GL. Perfectionism and academic difficulties in graduate students: Testing incremental prediction and gender moderation. Pers Individ Dif. 2018;123:223-228.

50. Onwuegbuzie AJ. Academic procrastinators and perfectionistic tendencies among graduate students. J Soc Behav Pers. 2000;15(5):103-109. 
51. Sheykhi M, Fathabadi J, Heidari M. The relations of anxiety, self-efficacy and perfectionism to dissertation procrastination. Developmental Psychology: Journal of Iranian Psychologists. 2013;9(35):283-296.

52. Witcher LA, Alexander ES, Onwuebuzie AJ, Collins KMT, Witcher AE. The relationship between psychology students' levels of perfectionism and achievement in a graduate-level research methodology course. Pers Individ Dif. 2007;43(6):13961405.

53. Frost RO, Heimberg RG, Holt CS, Mattia JI, Neubauer AL. A comparison of two measures of perfectionism. Pers Individ Dif. 1993;14(1):119-126.

54. Hays RD, Sherbourne CD, Mazel RM. The RAND 36-Item Health Survey 1.0. Health Econ. 1993;2:217-227. [PMID 8275167]

55. Ware JE, Sherbourne CD. The MOS 36-item short-form health survey (SF-36): I. Conceptual framework and item selection. Med Care. 1992;30(6):473-483. [PMID 1593914]

56. Coons SJ, Rao S, Keininger DL, Hays RD. A Comparative Review of Generic Quality-of-Life Instruments. Pharmacoeconomics. 2000;17(1):13.

57. Frisch MB. Quality of life inventory: Manual and treatment guide. Bloomington, MN: Pearson; 1994.

58. Frisch MB, Cornell J, Villanueva M, Retzlaff PJ. Clinical validation of the Quality of Life Inventory. A measure of life satisfaction for use in treatment planning and outcome assessment. Psychol Assess. 1992;4(1):92-101.

59. R: A language and environment for statistical computing [computer program]. Vienna, Austria: R Foundation for Statistical Computing; 2019.

60. Chang EC. Perfectionism as a predictor of positive and negative psychological outcomes: Examining a mediation model in younger and older adults. J Couns Psychol. 2000;47(1):18-26.

61. Balogun JA, Titiloye V, Balogun A, Oyeyemi A, Katz J. Prevalence and determinants of burnout among physical and occupational therapists. J Allied Health. 2002;31(3):131-139. [PMID 12227263]

62. Dyrbye LN, Thomas MR, Shanafelt TD. Systematic Review of Depression, Anxiety, and Other Indicators of Psychological Distress Among US and Canadian Medical Students. Acad Med. 2006;81(4):354-373. [PMID 16565188]

63. Rice KG, Ray ME, Davis DE, DeBlaere C, Ashby JS. Perfectionism and longitudinal patterns of stress for STEM majors: Implications for academic performance. J Couns Psychol. 2015;62(4):718-731. [PMID 26167648]

64. Chang EC. Perfectionism and dimensions of psychological well-being in a college student sample: A test of a stressmediation model. J Soc Clin Psychol. 2006;25(9):1001-1022.

65. Chang EC, Watkins A, Banks KH. How Adaptive and Maladaptive Perfectionism Relate to Positive and Negative Psychological Functioning: Testing a Stress-Mediation Model in Black and White Female College Students. J Couns Psychol. 2004;51(1):93-102.

66. Rice KG, Leever BA, Christopher J, Porter JD. Perfectionism, stress, and social (dis)connection: A short-term study of hopelessness, depression, and academic adjustment among honors students. J Couns Psychol. 2006;53(4):524-534.

67. Rice KG, Vergara DT, Aldea MA. Cognitive-affective mediators of perfectionism and college student adjustment. Pers Individ Dif. 2006;40(3):463-473.

68. Hewitt PL, Flett GL, Sherry SB, Caelian C. Trait Perfectionism Dimensions and Suicidal Behavior. In: Ellis TE, ed. Cognition and suicide: Theory, research, and therapy. Washington, DC, US: American Psychological Association; 2006:215-235.

69. Stoeber J, Noland AB, Mawenu TWN, Henderson TM, Kent DNP. Perfectionism, social disconnection, and interpersonal hostility: Not all perfectionists don't play nicely with others. Pers Individ Dif. 2017;119:112-117.

70. Gilman R, Rice KG, Carboni I. Perfectionism, perspective taking, and social connection in adolescents. Psychol Sch. 2014;51(9):947-959.

71. Gilman R, Adams R, Nounopoulos A. The interpersonal relationships and social perceptions of adolescent perfectionists. J Adolesc Res. 2011;21(2):505-511.

72. Chang EC, Rand KL. Perfectionism as a predictor of subsequent adjustment: Evidence for a specific diathesis-stress mechanism among college students. J Couns Psychol. 2000;47(1):129-137.

73. Curran T, Hill AP. Perfectionism is increasing over time: A meta-analysis of birth cohort differences from 1989 to 2016. Psychol Bull. 2017. [PMID 29283599]

74. Arana FG, Miracco MC, Galarregui MS, Keegan EG. A Brief Cognitive Behavioural Intervention for Maladaptive Perfectionism in Students: A Pilot Study. Behav Cogn Psychother. 2017;45(5):537-542. [PMID 28595666]

75. Beck AR, Verticchio H, Seeman S, Milliken E, Schaab H. A mindfulness practice for communication sciences and disorders undergraduate and speech-language pathology graduate students: Effects on stress, self-compassion, and perfectionism. Am J Speech Lang Pathol. 2017;26(3):893-907. [PMID 28776062]

76. Hayes SC, Luoma JB, Bond FW, Masuda A, Lillis J. Acceptance and commitment therapy: Model, processes and outcomes. Behav Res Ther. 2006;44(1):1-25.

77. Rizzolo D, Massey S. Fluctuations in stress over time during the first year of health science programs. J Allied Health. 2020; 49(20):128-132. 
78. Rice KG, Richardson CME. Classification challenges in perfectionism. J Couns Psychol. 2014;61(4):641-648. [PMID 25111705] 